\title{
How to Assess Proximal Femoral Shortening after Nailing of Proximal Femoral Fractures? A Short Review
}

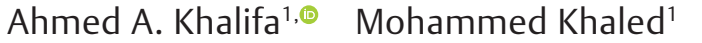 \\ ${ }^{1}$ Orthopaedic Department, Qena Faculty of Medicine and University \\ Hospital, South Valley University, Qena, Egypt \\ ${ }^{2}$ Qena Faculty of Medicine, South Valley University, Qena, Egypt
}

\author{
Address for correspondence Ahmed A. Khalifa, MD, FRCS, MSc, \\ Orthopaedic Department, Qena Faculty of Medicine and University \\ Hospital, South Valley University, Kilo 6 Qena-Safaga Highway, Qena \\ 83523, Egypt (e-mail: ahmed_adel0391@med.svu.edu.eg).
}

\begin{abstract}
Keywords

- shortening

- femoral fractures

- nailing

- hip biomechanics

Proximal femoral fractures (PFFs) are considered one of the most frequent situations faced by orthopaedic surgeons. Many lines of management had been described. Although management of PFFs with cephalomedullary nails (CMNs) is now considered the gold standard with many mechanical and biological advantages, this technique may have some disadvantages such as residual peritrochanteric pain, limping, limited walking distance, and difficulty with stairs. These complications may be attributed to fracture malreduction with shortening, which may result in either malunion or nonunion and ultimately implant failure. The resultant proximal femoral shortening (PFS) with alteration of the proximal femoral mechanics may affect both the hip abductor function and the daily patient activities. The purpose of this short review is to discuss the assessment and secondary effects of PFS after treating femoral fractures with CMNs.
\end{abstract}

\section{Introduction}

Proximal femoral fractures (PFFs) frequently occur in the elderly population, ${ }^{1}$ which represent a medical and socioeconomic burden, with a reported global annual incidence of approximately 1.3 million. ${ }^{2}$ This number is predicted to increase to about 6 million by the year 2050. ${ }^{3}$ Using cephalomedullary nails (CMNs) or the so-called proximal femoral nails (PFNs) for treating these fractures became the gold standard approach since its introduction in the $1980 \mathrm{~s} .{ }^{4-6}$ The minimal invasiveness of the procedure, early weight-bearing, the relative simplicity of the surgery, and theoretical mechanical advantages are considered the main benefits of using these devices. ${ }^{7.8}$
However, employing these devices has some complications, which may be considered serious, including iatrogenic neck of femur fractures, comminution and displacement of the trochanteric area, distortion of the proximal femoral anatomy, femoral head osteonecrosis, and residual symptoms. ${ }^{910}$ Persistent postoperative complaints such as residual peritrochanteric pain, limping, limited walking distance, and difficulty with stairs may be attributed to fracture malreduction, which may result in either malunion or nonunion and ultimate implant failure. ${ }^{11,12}$

Proximal femoral shortening (PFS) is a frequent finding after internal fixation of PFFs using CMNs, which may contribute to postoperative limping and walking limitation. ${ }^{13,14}$ Several reports have demonstrated an association

(C)2021. Medical and Surgical Update Society.

Medical and Surgical Update Society. This is an open access article published by Thieme under the terms of the Creative Commons Attribution-NonDerivative-NonCommercial-License, permitting copying and reproduction so long as the original work is given appropriate credit. Contents may not be used for commercial purposes, or adapted, remixed, transformed or built upon. (https://creativecommons. org/licenses/by-nc-nd/4.0/).

Thieme Medical and Scientific Publishers Pvt. Ltd. A-12, 2nd Floor, Sector 2, Noida-201301 UP, India 10.1055/s-0041-1730092 ISSN $2455-7420$ 
between PFS and reduced postoperative physical activity in these patients. ${ }^{15,16}$ Furthermore, PFS has been shown to have a negative effect on gait velocity, in addition to causing gait symmetry. ${ }^{15}$ According to Zlowodzki et al, ${ }^{14,16}$ most surgeons believe that PFS adversely affects the hip abductors' function and hip mobility and eventually cause a deficiency in patients' physical activity. Additionally, the resultant leg length discrepancy (LLD) may affect the spine, pelvis, and joints of the lower limbs. ${ }^{17}$

\section{Radiological Assessment of PFFs after Management Using PFNs}

On a proper anteroposterior (AP) view of the pelvis showing both sides with a known magnification of the X-ray or the presence of calibration (like a coin), evaluation is done as proposed by Paul et $\mathrm{al}^{18}{ }^{18}$ where they used the following approach (six steps for both sides on the AP X-ray) (-Fig. 1):

- Step 1: Define the shaft axis (F) by establishing two midpoints within the medullary canal. The first point is as distal on the X-ray as possible, and the other point is at the level of the distal margin of the lesser trochanter. Both points are connected with a line.

- Step 2: Define the femoral head center (C) by establishing the best-fitting circle over the femoral head. The circle center will be the femoral head center.

- Step 3: Identify the adjustment for leg rotation by measuring the length of the lag screw on the X-ray; then, compare this with the known lag screw length.

- Step 4: A line is then drawn from the femoral head center (C) to the two points located at the midpoint of the neck; this line represents the axis of the femoral neck $(\mathrm{N})$.

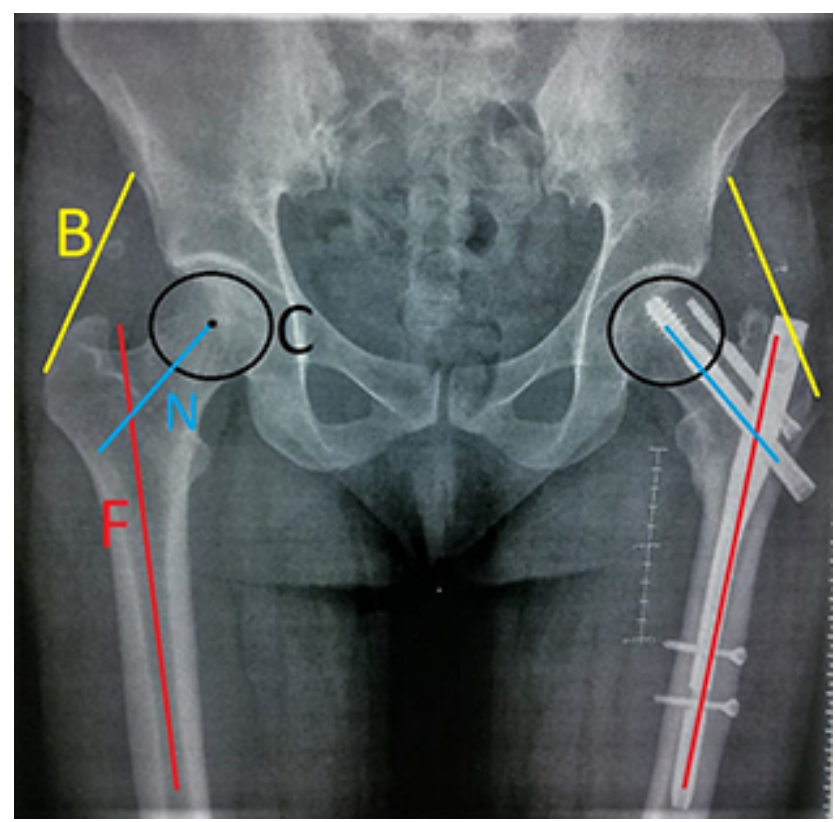

Fig. 1 Preliminary landmarks on AP pelvis radiographs showing both hips (C: center of the femoral head; $\mathrm{F}$ : the anatomical axis of the femur; B: the path of the abductor muscles; $\mathrm{N}$ : femoral neck axis).
- Step 5: A line is drawn tangential to the greater trochanter along with the shadow of the abductors, which represents the path of the abductor muscles (B).

- Step 6: Compare all the measurements with the healthy contralateral side.

\section{What Should Be Measured?}

- Femoral offset ( - Fig. 2A) is the length of a line from the femoral head center (C) passing perpendicular to the long axis of the femur (F). This measurement should be adjusted according to the determined leg rotation mentioned in step 3 . The average offset ranges from 41 to $44 \mathrm{~mm}$ and is related to the size of the femur. ${ }^{19}$

- Abductor lever arm (-Fig. 2B) is the length of a line drawn from the femoral head center $(C)$ to intersect the line of the path of the hip abductor muscles (B) at $90^{\circ} .^{20}$

- Neck-shaft angle (NSA) (-Fig. 3A) is defined as the angle between the long axis of the femoral shaft (F) and the long axis of the femoral neck (N). NSA is also known as the angle of the femoral neck. Normal NSA varies between $120^{\circ}$ and $140^{\circ} .{ }^{21}$

- Proximal femoral varusis defined as NSA of less than $120^{\circ}$, while femoral neck varus collapse is defined as a decrease in NSA greater than $10^{\circ}$ compared with the healthy contralateral side. ${ }^{14,16}$

- Lag screw telescoping (-Fig. 3B) is measured as the outer prominence of the lag screw from the edge of the nail or the lateral femoral cortex if intact (this value should be compared with the measurements recorded from the follow-up radiographs). ${ }^{18}$

- Leg length discrepancy ( $L L D$ ) (-Fig. 4A) is the distance from an identical point on the lesser trochanter on both sides to a fixed reference line (trans-teardrop line or trans-ischial line).

- Tip apex distance (-Fig. 4B) is the sum of the distance measured on both an AP radiograph and a lateral radiograph from the lag screw tip to the femoral head apex, after controlling for X-ray magnification. ${ }^{22}$

\section{Discussion}

The collapse of a comminuted intertrochanteric fracture usually occurs once the patient starts early weight-bearing, and this is considered one of the leading causes of PFS. Healing in this shortening position will affect both the hip offset and the abductor lever arm..$^{23-27}$

PFS leading to a distorted trochanteric-hip biomechanical relationship will negatively affect abductor muscle strength and may lead to persistent gait parameters deficiency. The effect of these biomechanical changes was described in details in the hip arthroplasty literature. ${ }^{20,28,29}$

Paul et al measured shortening as the lag screw telescoping through the lateral femoral cortex and the measured lag screw tip movement inside the femoral head. In their series, they found that the average lag screw telescoping through the proximal femur lateral cortex was approximately $3.3 \mathrm{~mm}$ 


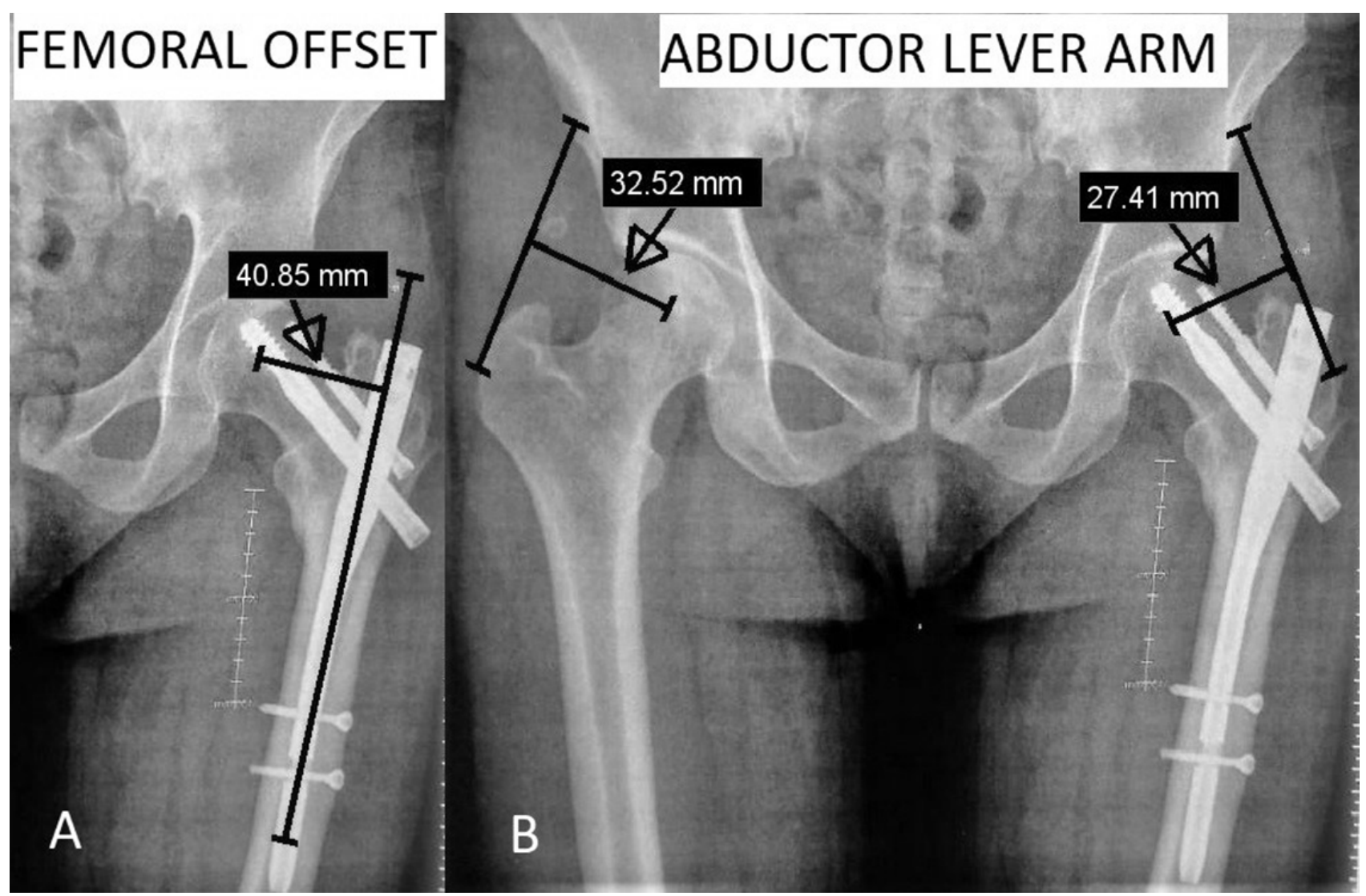

Fig. 2 Assessment of the femoral offset and the abductor lever arm. (A) Femoral offset: measured as the length of a line from the center of rotation of the femoral head (C) passing perpendicular to the long axis of the femur (F). (B) Abductor lever arm compared on both sides: the length of a line from the center of the femoral head (C) is drawn to intersect the line of the path of the abductor muscles (B) at 90.

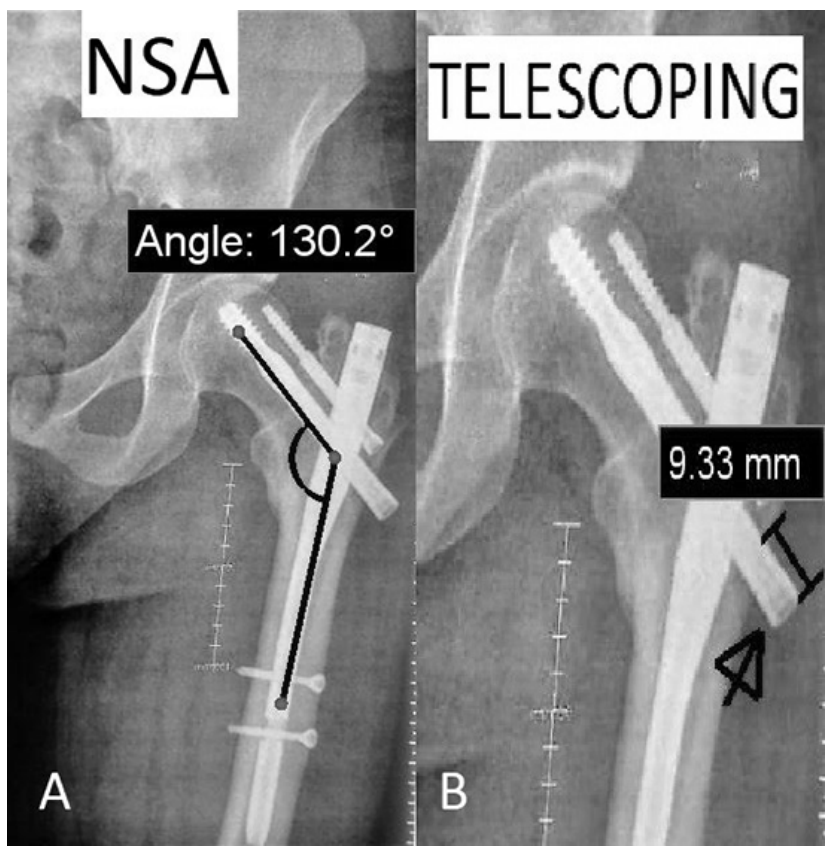

Fig. 3 Assessment of the femoral neck-shaft angle (NSA) and the presence of telescoping of the lag screw. (A) Femoral NSA: the angle between the long axis of the femoral shaft $(\mathrm{F})$ and long axis femoral neck (N). (B) Telescoping of the lag screw: measured as the lateral prominence of the lag screw to the edge of the nail. in an unstable fracture group and approximately $1.2 \mathrm{~mm}$ in a stable fracture group. The average lag screw tip migration inside the femoral head was $1.7 \mathrm{~mm}$. They concluded that proper fracture reduction and fixation would lead to the restoration of the hip biomechanics, which is mandatory for better functional outcomes. ${ }^{18}$

Gilat et al, in their study investigating the effect of PFS on the patient's functional outcomes, found that $43.5 \%$ of the patients experienced PFS that ranged from 5 to $9.9 \mathrm{~mm}$, while in $17 \%$ the shortening was more than $10 \mathrm{~mm}$. They concluded that PFS commonly occurs after intertrochanteric hip fractures fixation using CMNs, and this shortening is closely related to poor functional outcomes as well as early implant failure. ${ }^{30}$

McGrory et al $^{28}$ stated that femoral offset restoration and preservation of the abductor lever arm are correlated positively with the hip abduction strength as well as the range.

If the PFS is significant enough to cause a notable LLD, it may lead to secondary effects on the spine, causing compensatory scoliosis, which will aggravate further degenerative changes and low back pain. ${ }^{31}$ On contralateral hip and both knees, it may lead to asymmetric weight and force distribution on the joints, which may lead to degenerative changes. ${ }^{17}$ 


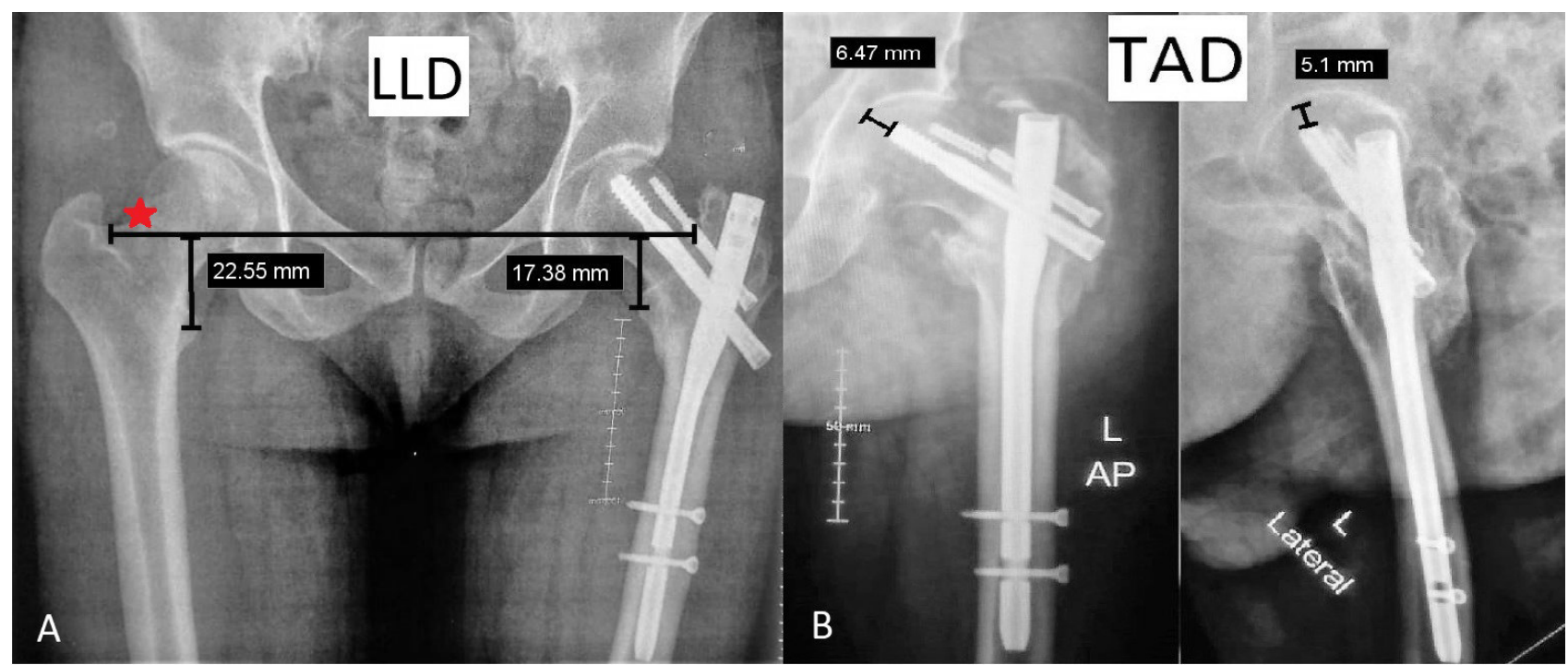

Fig. 4 Assessment of the leg length discrepancy and the tip apex distance. (A) Overall leg length discrepancy (LLD): the distance from an identical point on the lesser trochanter (LT) on both sides to a fixed reference line (trans-teardrop line*). (B) Tip apex distance (TAD) of the lag screw: the sum of the distance from the tip of the lag screw to the apex of the femoral head on an anteroposterior radiograph and this distance on a lateral radiograph.

\section{Conclusion}

The use of CMNs is considered the gold standard to treat PFFs. Although it has many advantages, alteration of proximal femoral mechanics is one of the common complications, especially PFS. Great care should be taken during surgery to restore the femoral length as well as to preserve the proximal femur biomechanics in comparison to the healthy side.

\section{Funding \\ None.}

\section{Conflict of Interest}

None declared.

\section{References}

1 Gullberg B, Duppe H, Nilsson B, et al. Incidence of hip fractures in Malmö, Sweden (1950-1991) Bone 1993;14(Suppl 1) :S23-S29

2 Ivanova N, Aibast H, Gapeyeva H, Kums T, Märtson A, Pääsuke $M$. Changes in hip muscle strength after proximal femoral fracture in elderly women. Acta Kinesiol Univ Tartuensis 2011;17:80-88

3 Kannus P, Parkkari J, Sievänen H, Heinonen A, Vuori I, Järvinen M. Epidemiology of hip fractures. Bone 1996;18(1(Suppl):57S $-63 \mathrm{~S}$

4 Gupta RK, Sangwan K, Kamboj P, Punia SS, Walecha P. Unstable trochanteric fractures: the role of lateral wall reconstruction. Int Orthop 2010;34(1):125-129

5 Schipper IB, Steyerberg EW, Castelein RM, et al. Treatment of unstable trochanteric fractures. Randomised comparison of the gamma nail and the proximal femoral nail. J Bone Joint Surg Br 2004;86(1):86-94

6 Calvert PT. The Gamma nail-a significant advance or a passing fashion? J Bone Joint Surg Br 1992;74(3):329-331

7 Anglen JO, Weinstein JN; American Board of Orthopaedic Surgery Research Committee. Nail or plate fixation of intertrochanteric hip fractures: changing pattern of practice. A review of the American Board of Orthopaedic Surgery Database. J Bone Joint Surg Am 2008;90(4):700-707

8 Bhandari M, Schemitsch E, Jönsson A, Zlowodzki M, Haidukewych GJ. Gamma nails revisited: gamma nails versus compression hip screws in the management of intertrochanteric fractures of the hip: a meta-analysis. J Orthop Trauma 2009;23(6):460-464

9 Yang KH, Han DY, Park HW, Kang HJ, Park JH. Fracture of the ipsilateral neck of the femur in shaft nailing. The role of CT in diagnosis. J Bone Joint Surg Br 1998;80(4):673-678

10 Bonnevialle P, Glasson JM, Determe P, Bellumore Y, Mansat M. Iatrogenic cervical fracture after femoral diaphyseal nailing [in French]. Rev Chir Orthop Repar Appar Mot 1999;85(4):397-403

11 Dodenhoff RM, Dainton JN, Hutchins PM. Proximal thigh pain after femoral nailing. Causes and treatment. J Bone Joint Surg $\mathrm{Br}$ 1997;79(5):738-741

12 Paterno MV, Archdeacon MT, Ford KR, Galvin D, Hewett TE. Early rehabilitation following surgical fixation of a femoral shaft fracture. Phys Ther 2006;86(4):558-572

13 Weil YA, Khoury A, Zuaiter I, Safran O, Liebergall M, Mosheiff R. Femoral neck shortening and varus collapse after navigated fixation of intracapsular femoral neck fractures. J Orthop Trauma 2012;26(1):19-23

14 Zlowodzki M, Ayeni O, Petrisor BA, Bhandari M. Femoral neck shortening after fracture fixation with multiple cancellous screws: incidence and effect on function. J Trauma 2008;64(1):163-169

15 Zielinski SM, Keijsers NL, Praet SF, et al. FAITH Trial Investigators. Femoral neck shortening after internal fixation of a femoral neck fracture. Orthopedics 2013;36(7):e849-e858

16 Zlowodzki M, Brink O, Switzer J, et al. The effect of shortening and varus collapse of the femoral neck on function after fixation of intracapsular fracture of the hip: a multi-centre cohort study. J Bone Joint Surg Br 2008;90(11):1487-1494

17 Khalifa A. Leg length discrepancy: assessment and secondary effects. Orthop Rheumatol 2017;6(1):1-5

18 Paul O, Barker JU, Lane JM, Helfet DL, Lorich DG. Functional and radiographic outcomes of intertrochanteric hip fractures treated with calcar reduction, compression, and trochanteric entry nailing. J Orthop Trauma 2012;26(3):148-154 
19 Rubin PJ, Leyvraz PF, Aubaniac JM, Argenson JN, Estève P, de Roguin B. The morphology of the proximal femur. A three-dimensional radiographic analysis. J Bone Joint Surg Br 1992;74(1):28-32

20 Lecerf G, Fessy MH, Philippot R, et al. Femoral offset: anatomical concept, definition, assessment, implications for preoperative templating and hip arthroplasty. Orthop Traumatol Surg Res 2009;95(3):210-219

21 Sinha R, Kumar B, Kumar S, Ratnesh R, Jawed Akhtar M, Fatima N. Study of neck shaft angle of femur in population of Bihar. Int J Res Med Sci 2017;5(11):4819

22 Goffin JM, Jenkins PJ, Ramaesh R, Pankaj P, Simpson AH. What is the relevance of the tip-apex distance as a predictor of lag screw cut-out? PLoS One 2013;8(8):e71195

23 Ahrengart L, Törnkvist H, Fornander P, et al. A randomized study of the compression hip screw and Gamma nail in 426 fractures. Clin Orthop Relat Res 2002;(401):209-222

24 Gardner MJ, Bhandari M, Lawrence BD, Helfet DL, Lorich DG. Treatment of intertrochanteric hip fractures with the AO trochanteric fixation nail. Orthopedics 2005;28(2):117-122

25 Hardy DC, Descamps PY, Krallis P, et al. Use of an intramedullary hip-screw compared with a compression hip-screw with a plate for intertrochanteric femoral fractures. A prospective, randomized study of one hundred patients. J Bone Joint Surg Am 1998;80(5):618-630

26 Kuzyk PR, Lobo J, Whelan D, Zdero R, McKee MD, Schemitsch $\mathrm{EH}$. Biomechanical evaluation of extramedullary versus intramedullary fixation for reverse obliquity intertrochanteric fractures. J Orthop Trauma 2009;23(1):31-38

27 Platzer P, Thalhammer G, Wozasek GE, Vécsei V. Femoral shortening after surgical treatment of trochanteric fractures in nongeriatric patients. J Trauma 2008;64(4):982-989

28 McGrory BJ, Morrey BF, Cahalan TD, An KN, Cabanela ME. Effect of femoral offset on range of motion and abductor muscle strength after total hip arthroplasty. J Bone Joint Surg Br 1995;77(6):865-869

29 Song KM, Halliday SE, Little DG. The effect of limb-length discrepancy on gait. J Bone Joint Surg Am 1997;79(11):1690-1698

30 Gilat R, Lubovsky O, Atoun E, Debi R, Cohen O, Weil YA. Proximal femoral shortening after cephalomedullary nail insertion for intertrochanteric fractures. J Orthop Trauma 2017;31(6):311-315

31 Stanitski DF. Limb-length inequality: assessment and treatment options. J Am Acad Orthop Surg 1999;7(3):143-153 